\title{
JUBILEE MEETING OF THE OPHTHALMOLOGICAL SOCIETY OF THE UNITED KINGDOM, I930
}

Provisional arrangements have been made for the Fiftieth Anniversary Meeting of the Ophthalmological Society from April 2 to 5, 1930. The Royal College of Surgeons is inviting members of the Society to a Reception at the College of Surgeons, on Thursday evening, April 3. By the courtesy of the Fishmongers' Company the Banquet will be held in the Fishmongers' Hall on Friday evening, April 4. The Bowman Lecture will be given by Sir Arthur Keith. His subject will be "The Genius of Sir William Bowman." The lecture will be given on the Friday afternoon at 5 p.m.

The subject of general discussion is " Disorders of Secretion of the Endocrine Glands associated with Eye Diseases " and will be opened by Mr. J. H. Fisher, Prof. H. Maclean, Dr. W. Clarke Souter and Prof. E. C. Dodds.

It will greatly facilitate the work of the Secretaries in making arrangements if members of the Society will intimate, as soon as possible, whether they intend to be present on this occasion, how many tickets they would like for the Reception at the College of Surgeons, and whether they wish to be present at the Banquet. It is probable that a certain number of tickets will be available for ladies as guests of members.

A number of distinguished foreign guests have been invited to attend as the guests of the Society and many of them have already sent in acceptances.

\section{TREATMENT OF RETINAL DETACHMENT}

THE treatment of " spontaneous " or " idiopathic " detachment of the retina in the past has been a disappointing matter in the experience of the vast majority of ophthalmic surgeons. Therapeutical and operative treatments have resulted in such a small percentage of cures, that one has at times been inclined to try any new method from which a cure is reported, but the resultant cynicism has tended to an impassive fatalism.

Good news from Switzerland concerning a new method of surgical intervention holds out hope of a lasting cure in quite a high proportion of cases. This method is due to J. Gonin, of Lausanne, who spoke at the Holland Congress of some of his cases in which the retina had remained in situ and had retained good vision three years and more after reposition. The effectiveness of his method has been endorsed by others who have made trial of 